\title{
Incidental discovery of a large complicated arteriovenous haemangioma
}

\author{
Alberto Anthony Goizueta, ${ }^{1}$ Peter Libbey, ${ }^{2}$ Anthony Moulton, ${ }^{3}$ Rabih El-Bizri ${ }^{4}$
}

IInternal Medicine, Roger Williams Medical Center, Boston University School of Medicine, Providence, Rhode Island, USA ${ }^{2}$ Department of Pathology, Roger Williams Medical Center, Boston University School of Medicine, Providence, Rhode Island, USA

${ }^{3}$ Department of Vascular/ Cardiothoracic Surgery, Roger Williams Medical Center, Boston University School of Medicine, Providence, Rhode Island, USA ${ }^{4}$ Pulmonary/Critical Care, Roger Williams Medical Center, Boston University School of Medicine, Providence, Rhode Island, USA

\section{Correspondence to}

Dr Rabih El-Bizri,

agoizueta85@gmail.com

Accepted 1 May 2017

\section{CrossMark}

To cite: Goizueta AA, Libbey P, Moulton A, et al. BMJ Case Rep Published Online First: [please include Day Month Year]. doi:10.1136/bcr-2016218759

\section{SUMMARY}

Arteriovenous haemangiomas within the chest are rare and uncommonly documented. After a 60-yearold woman with a history of smoking underwent a routine chest $X$-ray revealing a right apical mass, further investigations led to the discovery of a large extrapulmonary arteriovenous haemangioma in the superior mediastinum. Additionally, this case became complicated when the hemangioma was found to not only be compressing adjacent major arteries and veins, but also invading into the spinal canal and displacing the spinal cord. With multidisciplinary planning, the arteriovenous haemangioma was embolised and successfully resected. Thus, we present a case of an arteriovenous haemangioma in the superior mediastinum and discuss the importance of the case.

\section{BACKGROUND}

Arteriovenous haemangiomas (AVHs) are benign acquired vascular tumours characterised by a complex network of interconnecting arterial and venous shunts. In general, haemangiomas make up $0.5 \%$ of mediastinal masses, and of that only $1 \%$ are AVHs. ${ }^{1-3}$ Anatomically, the majority of haemangiomas in the mediastinum arise in the anterior mediastinum, with none reported in the superior mediastinum. ${ }^{1}$ This report describes a case of a large AVH with a complicated grid of vascular connections in the superior mediastinum.

\section{CASE PRESENTATION}

A 60-year-old woman with no significant medical history presented to the hospital after a routine chest $\mathrm{X}$-ray (CXR) reported a right apical lung mass suspicious for malignancy. The patient was asymptomatic and had a 10-pack year smoking history, a distant family history of unidentified cancer, no occupational hazards, and a normal physical examination and laboratory work-up. The initial CXR was followed by a contrast-enhanced CT of the chest, which showed an extrapulmonary mass measuring $7.3 \times 4.8 \times 6.8 \mathrm{~cm}$ in the medial aspect of the right apical thorax with marked compression of the brachiocephalic vein (figure 1). Additionally, there was extension of the mass into the T3-T4 neural foramen and destruction to the right side of the T2 vertebral body. Due to the involvement of the thoracic spine, an emergent MRI was performed to determine if there was any spinal cord involvement. The MRI of the thoracic spine confirmed there was a large mass invading through the T2-T3 neural foramen and into the spinal canal.
The invading tumour tracked up to the T1 vertebral body and displaced the spinal cord. Originally, there was a concern for malignancy, but a brain MRI and positive emission tomography scan were negative. A CT-guided biopsy of the mass was attempted first, but it provided a poor specimen showing only benign fibrovascular tissue. It was then determined that the mass required resection due to the possibility of it causing damage to the spinal cord.

\section{INVESTIGATIONS}

A CXR initially found the mass, but X-ray is inadequate to fully characterise the mass. Contrast-enhanced CT and MRI were used for better visualisation of the mass and the involvement on the adjacent structures including the spinal cord. Angiography was performed to determine the origin and extent of the tumour's blood supply. After biopsy and resection, histological staining with $\mathrm{H} \& \mathrm{E}$ was used to confirm the diagnosis of AVH.

\section{DIFFERENTIAL DIAGNOSIS}

The differential diagnosis of a superior mediastinal mass is not well defined, but includes diagnoses in the inferior mediastinum, which consists of the anterior, middle and posterior compartments. The differential diagnosis of an anterior mediastinal mass includes: thymoma, thyroid neoplasm, germ cell tumour and lymphoma; the middle mediastinum includes: cystic mass, cardiovascular aneurysm/anomaly, oesophageal tumour and lymphadenopathy; and the posterior mediastinum includes: neurogenic tumour, meningocele and thoracic spine lesions. The use of imaging techniques such as CT, MRI and angiography can help differentiate between the many possible diagnoses.

Imaging techniques are helpful in making a prehistological diagnosis, but once a haemangioma is suspected, a tissue specimen and staining is required. Haemangiomas can be subdivided into venous, arteriovenous, capillary, cavernous, angiomas, haemangiofibromas, fibroangioma and fibrolipohemangioma based on the histological findings. AVHs consist predominantly of many different-sized arteries and veins, which distinguishes them from other haemangiomas and confirms the diagnosis.

\section{TREATMENT}

Due to the complexity of the tumour, this became a multidisciplinary case and required multiple stages of intervention. Initially, neurosurgery was able to decompress the spinal cord with a laminectomy 


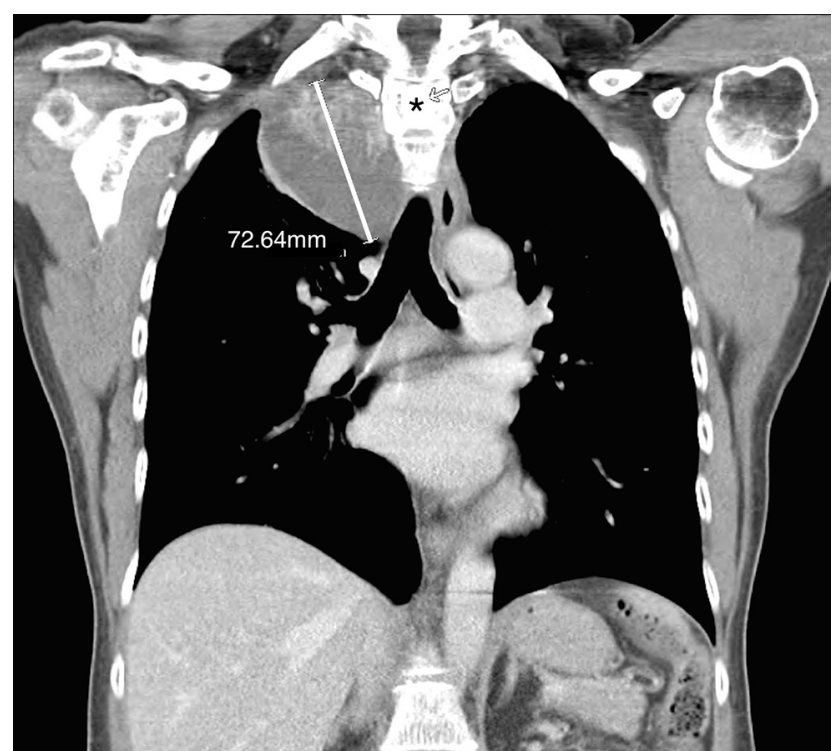

Figure 1 CT with contrast of right apical extrapulmonary arteriovenous haemangioma measuring approximately $7.3 \times 4.8 \times 6.8 \mathrm{~cm}$. Black asterisk represents $\mathrm{T} 2$ lytic lesion.

and partial tumor resection, but complete resection was aborted due to a large amount of bleeding. A posterior cervical thoracic fusion of the C6-T5 vertebrae was completed, but the mass was left incompletely resected. The specimen obtained during the resection was confirmed as a haemangioma on histology. After the initial surgery, the patient underwent magnetic resonance angiogram/magnetic resonance venogram, which reidentified the mass with partial extrinsic compression of the right subclavian artery and vein. Three months later, after a prolonged healing process, interventional radiology (IR) evaluated the case. IR used fluoroscopic angiography to identify the costocervical and thyrocervical trunks as the major contributing arteries to the tumour (figures 2 and 3). Due to the hypervascularity of the tumour, coil embolisation was used in the adjacent arteries to prevent non-target embolisation, and subsequently particle embolisation was used to achieve stasis of the major contributing arteries of the tumour (figures 2 and 3). Three days later, resection of the remaining tumour was performed by cardiothoracic and vascular surgery without any complications. The resected AVH was a well-demarcated tan/pink encapsulated mass that was easily detached from the surrounding structures (figure 4). Histology of this specimen confirmed an AVH with many intermediate-sized and large-sized arteriovenous structures (figure 5).

\section{OUTCOME AND FOLLOW-UP}

Although the first surgery was complicated and required additional intervention, the second procedure was successful without any major intraoperative complications. Potential postoperative complications include pneumothorax, collapsed lung, blood loss, nerve damage, infection and death. Our patient's only postoperative complication was a brief period of Horner's syndrome, which resolved, and she was successfully discharged from the intensive care unit on postoperative day 5. She continued with standard follow-ups over the next few months and her repeat imaging showed resolution of all postoperative side effects and no signs of tumour reoccurrence.

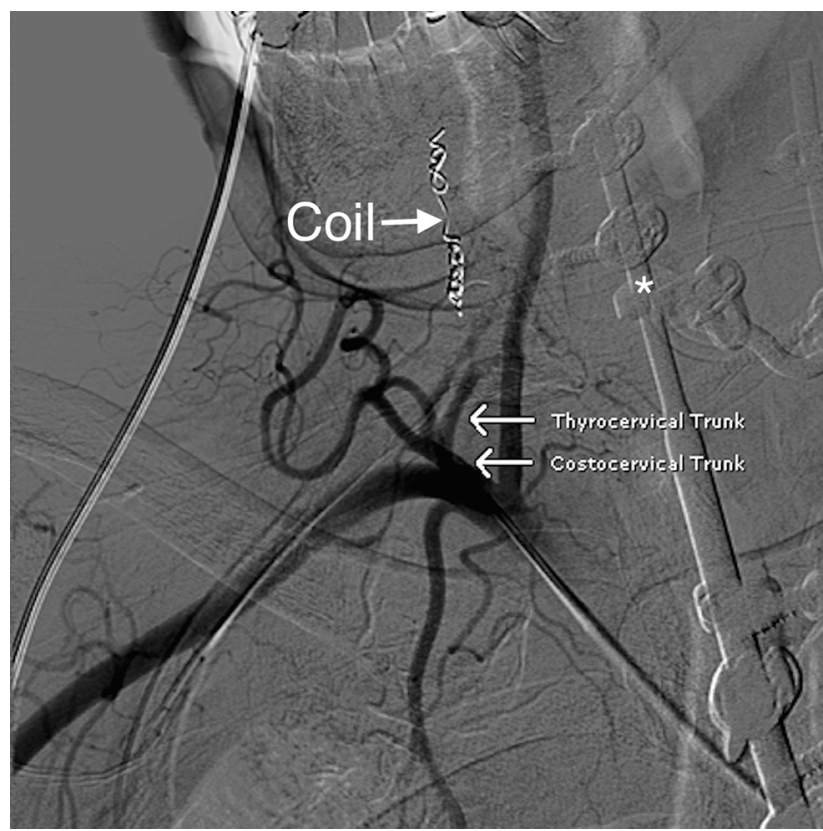

Figure 2 Angiogram of the arteriovenous haemangioma with major vasculature contributions from the thyrocervical and costocervical trunks. Coil embolisation of the ascending pharyngeal artery was also seen. Postoperative cervical thoracic fusion hardware in the background on the right side of the image (asterisk).

She continues to do well and has no adverse effects from her procedures.

\section{DISCUSSION}

Haemangiomas are rare vascular tumours that account for $0.5 \%$ of mediastinal masses. ${ }^{1}$ According to the literature, approximately 125 cases of mediastinal haemangiomas have been reported from 1914 to $2000 .^{3}$ Cavernous and capillary haemangiomas are the two major types of haemangiomas and account for $90 \%$ of mediastinal haemangiomas. Of the less common mediastinal haemangiomas, AVHs account for $1 \%$ of mediastinal haemangiomas, with the remaining $9 \%$ consisting of angiomas, haemangiofibromas, fibroangioma, fibrolipohemangioma and

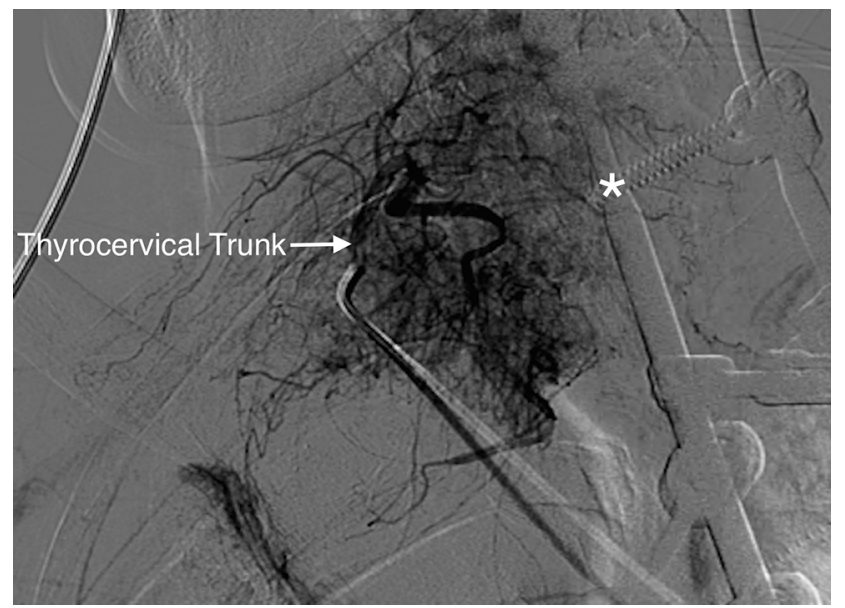

Figure 3 Angiogram of the hypervascular arteriovenous haemangioma with multiple small vessels from the thyrocervical trunk supplying the tumour. Postoperative cervical thoracic fusion hardware in the background on the right side of the image (asterisk). 


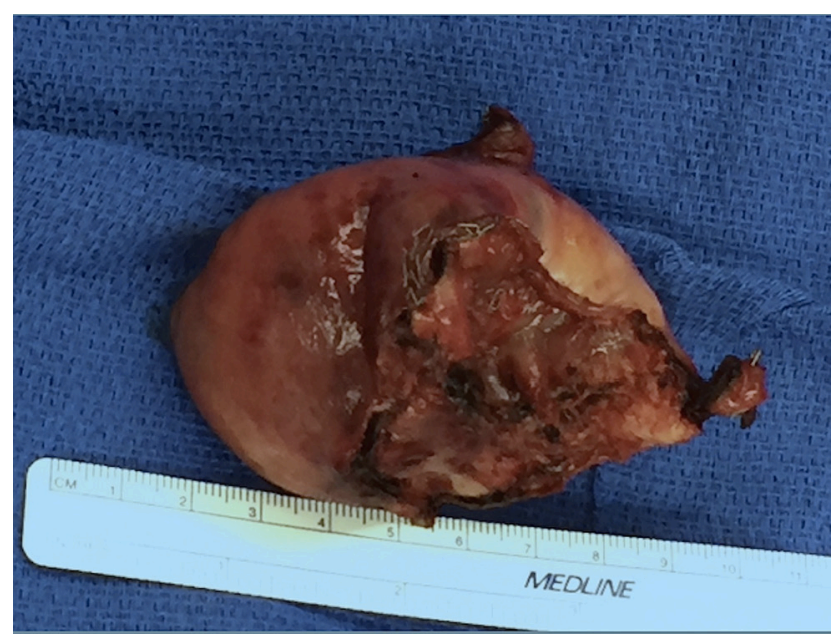

Figure 4 Gross specimen of a well-demarcated tan/pink arteriovenous haemangioma with a capsule measuring approximately $11 \mathrm{~cm}$.

venous haemangioma. ${ }^{1-3}$ Haemangiomas within the mediastinum most commonly arise in the anterior mediastinum (68\%), with the posterior $(22 \%)$ and middle (10\%) compartments found in decreasing incidence. ${ }^{3}$ Of note, to our knowledge, there have not been any reports of an AVH in the superior mediastinum.

There are two main types of AVHs, which are categorised into either a deep or superficial form. ${ }^{14}$ Superficial AVHs are the most common and are usually found in children, adolescents and young adults. ${ }^{1}$ The superficial form most frequently affects the head and neck, is localised to the dermis and submucosa of the lips and perioral skin, and produces a reddish blue skin discolouration. Deep AVHs are seen in middle-aged and elderly adults. The deep form most often affects the head, neck and lower extremities, but is not easily visualised when compared with a superficial AVH. Our patient had an asymptomatic deep $\mathrm{AVH}$ in the superior mediastinum with involvement of the vertebrae and invasion into the spinal canal. Although the incidence of a vertebral haemangioma is approximately $10 \%$, only about $1 \%$ invade the spinal canal or paravertebral space. ${ }^{5}$ Approximately $40 \%$ of AVHs are asymptomatic and the remainder may produce mild pain and intermittent bleeding. ${ }^{2}$ These lesions will

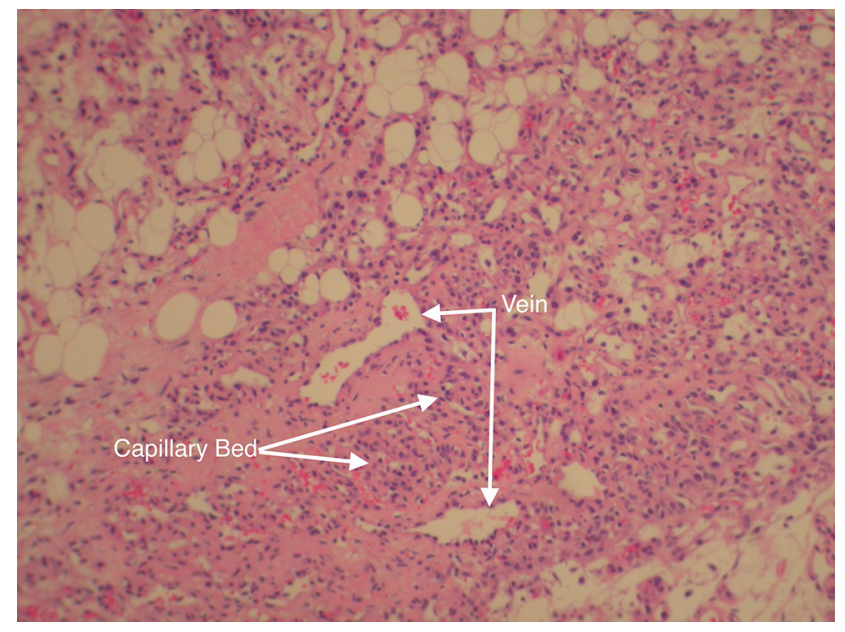

Figure 5 Histology of the arteriovenous haemangioma consisting of small-sized to intermediate-sized vessels with arteriovenous features. Small capillary and larger venous-sized channels seen here. $\mathrm{H} \& \mathrm{E}$ magnification $10 x$. grow proportionately with the patient and will not involute like capillary haemangiomas. Additionally, certain conditions such as sepsis, trauma, puberty and pregnancy are thought to exacerbate the growth of these tumours.

While the aetiology of an AVH is unknown, there are a few explanatory hypotheses. Some of the postulated mechanisms include the persistence of fetal capillary beds, multicentric hamartomatous proliferation of vessels of the dermal subpapillary plexus, trauma, endocrine and inflammatory stimuli activating an underlying vascular malformation, and chronic liver disease. ${ }^{4}$ Another interesting finding related to the aetiology of AVHs is the presence of an abnormal amount of mast cells surrounding the tumours. ${ }^{46}$ Mast cells contain granules rich in heparin and histamine, which can stimulate the proliferation of endothelial cells resulting in angiogenesis. ${ }^{4}$ All of these mechanisms are plausible, but at this time none have been proven to be the underlying cause responsible for the formation of AVHs.

The diagnosis of an AVH is confirmed by histology, but certain imaging modalities can assist in a prehistological diagnosis. Chest radiographs can reveal the presence of a mass, if large enough, as well as surrounding bone and soft tissue hypertrophy or atrophy. Similarly, our patient's CXR detected bony destruction adjacent to the mass (figure 1). A CXR is not adequate to determine the origin or the extent of involvement of an AVH. The use of contrast-enhanced CT is more beneficial because it is able to delineate the mass, the surrounding structures and the involvement of the mass on those adjacent structures. A contrast-enhanced CT scan will show the haemangioma as centrally heterogeneous and may have pointed enhancements at the borders of the tumour called 'peripheral puddles' (figure 1). These are formed by the accumulation of blood at the tumour periphery and are characteristic of AVHs. ${ }^{13}$ MRI was useful in identifying the neuroanatomy, and determining mass effect on the spinal cord and the urgency for intervention. A T2-weighted MRI will show the tumour with high signal intensity, and on both MRI and CT phleboliths may be present. However, phleboliths are only seen in $10 \%$ of cases. ${ }^{137}$ CT and MRI are helpful in identifying the involvement of an AVH, but angiography has the most benefit in determining a prehistological diagnosis. Angiography can also determine the origin of the blood supply and visualise early filling and draining of the large tortuous arterial and venous system, which is due to the presence of shunts. ${ }^{6}$ Additionally, angiography allows for therapeutic intervention if necessary. Histology is the best technique to subtype and confirm the diagnosis of an AVH. Histologically, the use of H\&E stain under microscopy will show a well-circumscribed tumour with multiple anastomosing arteries, veins and capillaries of different sizes in close proximity to one another. ${ }^{4-10}$ Occasionally, an arteriovenous shunt can be appreciated as well. ${ }^{49}$

The treatment of an AVH is determined by the significance of symptoms and the adjacent involvement produced by the tumour. ${ }^{5}$ In a patient with a small AVH that is asymptomatic, it is reasonable to take non-operative measures and periodically observe the tumour. ${ }^{5}$ In a patient with a larger and/or symptomatic AVH, surgical resection should be considered. ${ }^{5}$ An AVH can be difficult to resect due to complexed vascular malformations, which have a tendency to bleed. Specifically, the resection of a deep AVH becomes dangerous due to the inability to easily control bleeding in a much more difficult location. IR has become invaluable in this situation through its ability to use angiography and embolise major contributing vessels prior to surgery, which reduces intraoperative bleeding. ${ }^{11}$ This was apparent with our patient's tumour. During the initial neurosurgical procedure, IR was not used due to the urgency to intervene before there was 
worsening of the spinal cord involvement, which unfortunately led to a large amount of bleeding and incomplete resection of the tumour. Luckily, with assistance from IR, we were able to identify branches of the costocervical and thyrocervical arteries as the major vascular supply to the tumour before the second surgery. With this information, the patient underwent successful embolisation of the vessels and we were able to avoid unnecessary complications. In regard to complete versus partial resection, complete resection of an $\mathrm{AVH}$ is recommended due to the ability to reoccur if incompletely resected. ${ }^{1}$

In conclusion, after a 60-year-old woman was found to have a right apical mass on CXR, further investigation led to the

\section{Patient's perspective}

The transition from healthy to requiring such a risky surgery was scary. The complications from the first surgery made me even more worried about going through another surgery. The pain and recovery after surgery was difficult, but I'm very happy with the results and happy to be done.

\section{Learning points}

- Arteriovenous haemangiomas are very uncommon, but should be considered in the differential for mediastinal masses.

- Although histology confirms the diagnosis, imaging modalities can assist in a prehistological diagnosis.

- Resection of arteriovenous haemangiomas can be very complicated due their ability to form complex grids of arteriovenous connections.

- Complete resection of the tumour is required due to its ability to reoccur if remnants of the tumour are left behind.

- A multidisciplinary team including pulmonary medicine, cardiothoracic surgery and interventional radiology can play an integral role in management. discovery of a large complex extrapulmonary AVH in the superior mediastinum. AVHs are rare, and to our knowledge there have been no previous cases reported in the superior mediastinum. We determined this AVH originated from the branches of the costocervical and thyrocervical trunk, and due to its large size it compressed adjacent major vessels, invaded into the spinal canal and displaced the spinal cord. After planning with our multidisciplinary team consisting of pulmonary medicine, cardiothoracic surgery, vascular surgery, neurosurgery and IR, the tumour's contributing vessels were embolised, allowing for a successful resection.

Contributors All authors have contributed to the manuscript. AAG wrote the manuscript. AM and PL reviewed and/or edited sections of the manuscript per their specialisations. RE-B reviewed and edited the entire manuscript.

Competing interests None declared.

Patient consent Obtained.

Provenance and peer review Not commissioned; externally peer reviewed.

(c) BMJ Publishing Group Ltd (unless otherwise stated in the text of the article) 2017. All rights reserved. No commercial use is permitted unless otherwise expressly granted.

\section{REFERENCES}

1 Mizutani E, Morita R, Kitamura S. Arteriovenous hemangioma in the middle mediastinum: report of a case. Surg Today 2011;41:846-8.

2 Yun T, Suzuki H, Tagawa T, et al. Cavernous hemangioma of the posterior mediastinum with bony invasion. Gen Thorac Cardiovasc Surg 2016;64:43-6.

3 Yoshino $\mathrm{N}$, Okada D, Ujiie $\mathrm{H}$, et al. Venous hemangioma of the posterior mediastinum. Ann Thorac Cardiovasc Surg 2012;18:247-50.

4 Koutlas IG, Jessurun J. Arteriovenous hemangioma: a clinicopathological and immunohistochemical study. J Cutan Pathol 1994;21:343-9.

5 Dang L, Liu C, Yang SM, et al. Aggressive vertebral hemangioma of the thoracic spine without typical radiological appearance. Eur Spine J 2012;21:1994-9.

6 DeSchryver-Kecskemeti K, Williamson JR, Jakschik BA, et al. Mast cell granules within endothelial cells: a possible signal in the inflammatory process? Mod Pathol 1992;5:343.

7 Kara M, Dikmen E, Dizbay Sak S, et al. Intercostal arteriovenous hemangioma. Eur J Cardiothorac Surg 2000;18:622-4.

8 Weissferdt A, Moran CA. Primary vascular tumors of the lungs: a review. Ann Diagn Pathol 2010;14:296-308.

9 Ahn $\mathrm{S}$, Jung $\mathrm{S}, \mathrm{Cho} \mathrm{JH}$, et al. A rare case of pulmonary arteriovenous hemangioma presenting as a Peribronchial Mass. J Pathol Trans/ Med 2016;50:243-5.

10 Moran CA, Suster S. Mediastinal hemangiomas: a study of 18 cases with emphasis on the spectrum of morphological features. Hum Pathol 1995;26:416-21.

11 McAdams HP, Rosado-de-Christenson ML, Moran CA. Mediastinal hemangioma: radiographic and CT features in 14 patients. Radiology 1994;193:399-402.

Copyright 2017 BMJ Publishing Group. All rights reserved. For permission to reuse any of this content visit http://group.bmj.com/group/rights-licensing/permissions.

BMJ Case Report Fellows may re-use this article for personal use and teaching without any further permission.

Become a Fellow of BMJ Case Reports today and you can:

- Submit as many cases as you like

- Enjoy fast sympathetic peer review and rapid publication of accepted articles

- Access all the published articles

- Re-use any of the published material for personal use and teaching without further permission

For information on Institutional Fellowships contact consortiasales@bmjgroup.com

Visit casereports.bmj.com for more articles like this and to become a Fellow 